УДК 631: 631.821: 631.816

https://doi.org/10.32634/0869-8155-2021-351-7-8-52-60

Краткий обзор/Brief review

Ивенин А.В. 1

Саков А.П. ${ }^{1}$

Богомолова Ю.А. ${ }^{1}$,

Бузынина Т.C. ${ }^{1}$,

Ивенин В.В. ${ }^{2}$

${ }^{1}$ Нижегородский научно-исследовательский институт сельского хозяйства - филиал ФГБНУ «Федеральный аграрный научный центр Северо-Востока имени Н.В. Рудницкого", Российская Федерация, Нижегородская область, Кстовский район, с.п. Селекционной станции, д.3 8, 607686 E-mail:a.v.ivenin@mail.ru

2 ФГБОУ ВО «Нижегородская государственная сельскохозяйственная академия», Российская Федерация, г. Нижний Новгород, проспект Гагарина, д. 97, 603107

Ключевые слова: интенсивность дыхания почвы, биологическая активность почвы, минеральные удобрения, доломитовая мука, длительный стационарный опыт, урожайность

Для цитирования: Ивенин А.В., Саков А.П., Богомолова Ю.А., Бузынина Т.С., Ивенин В.В. Влияние внесения минеральных удобрений и длительного последействия известкования на биологические свойства светло-серой лесной почвы и урожайность клевера лугового 1г. п. в условиях юго-востока Волго-Вятского региона. Аграрная наука. 2021; 351 (7-8): 52-60.

https://doi.org/10.32634/0869-8155-2021-351-7-8-52-60

Конфликт интересов отсутствует

Alexey V. Ivenin ${ }^{1}$,

Alexander P. Sakov ${ }^{1}$,

Yuliya A. Bogomolova 1

TatianaS . Buzynina ${ }^{1}$,

Valentin V. Ivenin ${ }^{2}$

${ }^{1}$ Nizhny Novgorod Research Institute of Agriculture - branch of the Federal Agrarian

Research Center of the North-East named after N.V. Rudnitsky, Russian Federation, Nizhny Novgorod region, Kstovsky district, s.p. Selektsionnoy station, 38, 607686

E-mail:a.v.ivenin@mail.ru

${ }^{2}$ Nizhny Novgorod State Agricultural Academy, Nizhny Novgorod, 97 Gagarin Avenue, 603107 Russian Federation

Key words: soil respiration rate, biological activity of the soil, mineral fertilizers, dolomite flour, long-term stationary experience, yield

For citation: Ivenin A.V., Sakov A.P., Bogomolova Yu.A., Buzynina T.S., Ivenin V.V. The effect of mineral fertilizers and long-term aftereffect of liming on the biological properties of light gray forest soil and the yield of meadow clover $1 \mathrm{~g} . \mathrm{p}$. in the conditions of the South-East of the Volga-Vyatka region. Agrarian Science. 2021; 351 (7-8): 52-60. (In Russ.)

https://doi.org/10.32634/0869-8155-2021-351-7-8-52-60

There is no conflict of interests

Влияние внесения минеральных удобрений и длительного последействия известкования на биологические свойства светло-серой лесной почвы и урожайность клевера лугового 1 г.п. в условиях юго-юостока Волго-Вятского региона

\title{
PEЗЮME
}

В статье говорится о влиянии внесения минеральных удобрений и длительного последействия известкования на биологические свойства светло-серой лесной почвы и урожайность клевера лугового 1г. п. в условиях юго-востока Волго-Вятского региона. На биологические свойства светло-серой лесной почвы в 2020 году в большей степени повлияли погодные условия вегетации клевера розового и сама культура, чем исследуемое последействие известкового материала и различные дозы минерального питания. Биологическая активность почвы находилась в интервале 16,3-30,4\%. Интенсивность дыхания почвы- о чень слабая, находилась в интервале 1,53-3,4 мг $\mathrm{CO}_{2} / 10 г$ за 24 ч. Средняя урожайность зеленой массы клевера 1 г.п. (в пересчете на абсолютно сухое вещество) составила 30,4-33,2 т/га (HCP 05 по фактору В-6,3) и не зависела от последействия изучаемых доз извести. Применение $\mathrm{N}_{45} \mathrm{P}_{120} \mathrm{~K}_{180}$ доз минеральных удобрений повышает среднюю урожайность клевера розового1 г.п. по сравнению с естественным плодородием светло-серой лесной почвы и вариантами применения $\mathrm{N}_{15} \mathrm{P}_{40} \mathrm{~K}_{60}$ доз до 37,9 т/га, что на 11,9 и 8,6 т/га соответственно выше данных вариантов (НСР 05 по фактору A-5,2). Прибавка получена и от применения $\mathrm{N}_{30} \mathrm{P}_{80} \mathrm{~K}_{120}$ доз минеральных удобрений по сравнению с выращиванием клевера по естественному плодородию почвы - на 7,4 т/га ( $\mathrm{HCP}_{05}$ по фактору A-5,2). В целом за 42 года изучения последействия известкования показано, что оно к 2020 году не влияет в условиях юго-востока Волго-Вятского региона на биологические свойства светло-серой лесной почвы и урожайность клевера 1 г.п. по всем изучаемых дозам его применения. Почва нуждается в проведении повторных мелиоративных работ.

\section{The effect of mineral fertilizers and long-term aftereffect of liming on the biological properties of light gray forest soil and the yield of meadow clover $1 \mathrm{~g} . \mathrm{p}$. in the conditions of the South-East of the Volga-Vyatka region}

\section{ABSTRACT}

The article deals with the influence of mineral fertilizers and the long-term aftereffect of liming on the biological properties of light gray forest soil and the yield of meadow clover 1 g.p. in the conditions of the South-East of the Volga-Vyatka region. The biological properties of light gray forest soil in 2020 were more influenced by the weather conditions of the pink clover vegetation and the culture itself than by the studied aftereffects of lime material and various doses of its mineral nutrition. The biological activity of the soil was in the range of $16.3-30.4 \%$. The intensity of soil respiration was very weak and was in the range of $1.53-3.4 \mathrm{mg}$ of $\mathrm{CO}_{2} / 10 \mathrm{~g}$ for 24 hours. The average yield of the green mass of clover $1 \mathrm{~g} . \mathrm{p}$. (in terms of absolutely dry matter) was in the range of 30.4-33.2 t/ha (NSR $_{05}$ by factor B-6.3) and did not depend on the aftereffect of the studied lime doses. The use of $\mathrm{N}_{45} \mathrm{P}_{120} \mathrm{~K}_{180}$ doses of mineral fertilizers increases the average yield of pink clover 1 g.p. compared with the natural fertility of light gray forest soil and the variants of using $\mathrm{N}_{15} \mathrm{P}_{40} \mathrm{~K}_{60}$ doses up to $37.9 \mathrm{t} / \mathrm{ha}$, which is by 11.9 and $8.6 \mathrm{t} /$ ha respectively higher than these variants (NSR ${ }_{05}$ for factor A-5.2). An increase was also obtained from the use of $\mathrm{N}_{30} \mathrm{P}_{80} \mathrm{~K}_{120}$ doses of mineral fertilizers compared to the cultivation of clover according to natural soil fertility - by $7.4 \mathrm{t} / \mathrm{ha}\left(\mathrm{NSR}_{05}\right.$ according to factor A-5.2).I $\mathrm{n}$ general, for 42 years of studying the aftereffect of liming it was shown, that by 2020 liming does not affect the biological properties of light gray forest soil and the yield of $1 \mathrm{~g} . \mathrm{p}$. clove according to all the studied doses of its use in the conditions of the South-East of the Volga-Vyatka region. The soil needs repeating of reclamation works.

Поступила: 10 июня

После доработки: 15 июня

Принята к публикации: 10 сентября
Received: 10 June

Revised: 15 June

Accepted: 10 september 


\section{Введение}

Основой устойчивого функционирования агропромышленного комплекса в условиях интенсивного ведения сельскохозяйственного производства является сохранение и повышение почвенного плодородия, что невозможно без активизации биологических процессов, проходящих в почве, и почвенной микрофлоры [1, 2], стимулирование которой, в свою очередь, будет способствовать повышению, а главное стабилизации урожаев сельскохозяйственных культур, в частности урожая зеленой массы клевера лугового, рост и развитие которого зависят от развития почвенной биоты и в том числе и симбиотических клубеньковых бактерий [3]

В современных условиях сельскохозяйственного производства одним из наиважнейших параметров является известкование. Избыточная кислотность среды, особенно при высоком содержании активного алюминия, является одной из главных причин низкой продуктивности сельскохозяйственных культур и ряда отрицательных экономических и экологических последствий. В частности, на этих почвах на 30-40\% снижается эффективность минеральных удобрений, снижается активность почвенной микрофлоры, тем самым снижается интенсивность биологических процессов, протекающих в них (изменяются ее биологические свойства) $[4,5,6]$. Главным источником пополнения почвенных запасов и удовлетворения потребности растений в элементах питания являются удобрения, которые являются мощным фактором повышения плодородия почвы, в том числе способствуют развитию почвенной микрофлоры, растительных объектов, тем самым активно влияют на биологические свойства самих почв и в итоге на урожайность сельскохозяйственных культур [7].

Поэтому возникает необходимость не только в повышении плодородия почвы и увеличении, а главное стабилизации урожаев сельскохозяйственных культур, но и в рационализации пользования земельными ресурсами, что невозможно без использования средств химизации, в частности минеральных удобрений и из весткования [4, 8].

Цель исследований - изучить влияние минеральных удобрений и последействия различных доз извести на урожайность клевера лугового 1 гп., целлюлозолитическую активность и интенсивность дыхания светло-серой лесной почвы в условиях юго-востока Волго-Вятского региона.

\section{Материал и методы}

Исследования проведены в длительном стационарном опыте, заложенном в 1978 г. на опытном поле Нижегородского НИИСХ - филиала ФГБНУ ФАНЦ Северо-Востока.

Климат Нижегородской области умеренно-конти нентальный со среднемноголетним значением гидротермического коэффициента (ГТК) в весенне-летний период - 1,24.

Почва опытного участка светло-серая лесная легкосуглинистая среднекислая $\left(\mathrm{pH}_{\mathrm{KCl}}\right.$ 4,3 ), слабогумусированная (гумус $-1,6 \%)$, высокообеспеченная подвижными формами фосфора (270 мг/кг) и калия (225 мг/кг).

Опыт проводили по следующей схеме: фактор А - известкование в дозах по 0; 1,0; 2,0 г.к.; фактор Б разные дозы минерального питания: без удобрений - (NPK)0, оди- нарная - $(\mathrm{NPK})_{1}$, двойная $-(\mathrm{NPK})_{2}$, тройная $-(\mathrm{NPK})_{3}$ Полевой опыт включает 12 вариантов, повторность 4-кратная, расположение делянок в опыте рендомизированное. Общая площадь делянки - $108 \mathrm{~m}^{2}$, учетная $64 \mathrm{M}^{2}$.

Сельскохозяйственные культуры изучаются в ротации 8-севооборота: вико-овсяная смесь+ к левер; клевер 1, 2, 3 г.п.; озимая пшеница; картофель; яровая пшеница; ячмень.

В 2019 г. пошла шестая ротация севооборота, которая началась с выращивания вико-овсяной смеси с одновременным подсевом клевера. В 2020 году в полевом опыте проводили наблюдения и анализы в посевах клевера 1-го года пользования, который будет культивироваться в полевом опыте до 2022 г.

Доломитовая мука внесена единожды при закладке опыта в 1978 году. Минеральные удобрения вносились в соответствии со схемой (табл. 1).

Агротехника возделывания клевера 1 г.п.: клевер подсевался под покровную культуру (вико-овсяная смесь) в 2019 г.; внесение минеральных удобрений проводили согласно схеме опыта вразброс вручную 20 апреля 2020 г., применяли диаммофоску и хлористый калий, с последующей их заделкой боронованием посевов зубовыми боронами БЗСС-1,0. Уборку клевера 1 г.п. на зеленую массу проводили при помощи роторной косилки $\mathrm{KPH}-2,1$ в фазу бутанизации - начала цветения 18 июня 2020 г. Сорт клевера розового - Мартум.

Методики проводимых исследований: учет зеленой массы клевера 1 г.п. проводился сплошным методом; биологическую активность почвы определяли методом «аппликаций» Е.Н. Мишустина и А.Н. Петровой; определение интенсивности дыхания почвы - по методу А.Ш. Галстяна; математическая обработка результатов исследований - по Б.А. Доспехову с использованием программы статистической обработки Statist.

\section{Результаты и их обсуждение}

Важный показатель плодородия почв - это биологическая активность. Под биологической активностью почвы понимают совокупность биологических процессов, протекающих в почве. Биологическая активность основана на способности живых организмов почвы осуществлять процессы разложения и синтеза веществ. Уровень биологической активности зависит от количественного и качественного состава почвенных организмов (бактерий, актиномицетов, дрожжей, простейших, водорослей, червей и др.).

Определяли биологическую активность почвы методом «аппликаций». Льняные полотна были заложены в почву 14 мая 2020 г., извлечены через 60 суток. Результаты наблюдений представлены в таблице 2, из которой видно, что при погодных условиях 2020 года, которые были в целом благоприятны для роста и развития растений клевера 1 г.п. (ГТК за май и июнь составил 1,4, средний многолетний ГТК-1,3), увеличение показателя биологической активности почвы по сравнению с кон-
Таблица 1. Дозы минеральных удобрений под культуры звена севооборота, кг д. в./га (шестая ротация севооборота)

Table 1. Doses of mineral fertilizers for crops of the crop rotation link, $\mathbf{k g} \mathbf{~ d . ~ v . / h a ~ ( s i x t h ~ r o t a t i o n ~ o f ~}$ the crop rotation)

\begin{tabular}{|c|c|c|c|c|c|c|c|c|c|c|}
\hline \multirow{2}{*}{ Год } & \multirow{2}{*}{ Культура } & \multicolumn{3}{|c|}{ Одинарная доза } & \multicolumn{3}{|c|}{ Двойная доза } & \multicolumn{3}{|c|}{ Тройная доза } \\
\hline & & N & $\mathrm{P}_{2} \mathrm{O}_{5}$ & $\mathrm{~K}_{2} \mathrm{O}$ & N & $\mathrm{P}_{2} \mathrm{O}_{5}$ & $\mathrm{~K}_{2} \mathrm{O}$ & N & $\mathrm{P}_{2} \mathrm{O}_{5}$ & $\mathrm{~K}_{2} \mathrm{O}$ \\
\hline 2020 & Клевер 1 г.п. & 15 & 40 & 60 & 30 & 80 & 120 & 45 & 120 & 180 \\
\hline
\end{tabular}


Таблица 2. Изменение биологических свойств светло-серой лесной почвы на различных фонах минеральных удобрений и последействия разных доз известкования

Table 2. Changes in the biological properties of light gray forest soil on different backgrounds of mineral fertilizers and the aftereffect of different doses of liming

\begin{tabular}{|c|c|c|c|}
\hline $\begin{array}{l}\text { № } \\
\pi / \Pi\end{array}$ & Вариант & $\begin{array}{c}\text { Интенсивность дыхания, мг } \\
\mathrm{CO}_{2} / 10 \text { г } 3 а 24 \text { ч }\end{array}$ & $\begin{array}{c}\text { Степень разложения льняного } \\
\text { полотна, \% (экспозиция } 60 \text { суток) }\end{array}$ \\
\hline 1 & Контроль & 1,53 & 16,3 \\
\hline 2 & Са 1,0 г.к. & 2,27 & 30,4 \\
\hline 3 & Са 2,0 г.к. & 2,62 & 24,8 \\
\hline 4 & $(\mathrm{NPK})_{1}-$ Фон 1 & 2,95 & 22,9 \\
\hline 5 & Фон 1 + Са 1,0 г.к. & 1,62 & 22,6 \\
\hline 6 & Фон 1 + Са 2,0 г.к. & 2,77 & 21,7 \\
\hline 7 & $(\mathrm{NPK})_{2}-$ фон 2 & 2,60 & 21,7 \\
\hline 8 & Фон 2 + Са 1,0 г.к. & 1,75 & 28,1 \\
\hline 9 & Фон 2 + Са 2,0 г.к. & 2,94 & 24,8 \\
\hline 10 & $(\mathrm{NPK})_{3}-$ фон 3 & 2,75 & 23,4 \\
\hline 11 & Фон 3 + Са 1,0 г.к. & 3,37 & 26,0 \\
\hline 12 & Фон 3 + Са 2,0 г.к. & 3,40 & 24,8 \\
\hline & $\mathrm{HCP}_{05}$ & 1,88 & 9,6 \\
\hline
\end{tabular}

Таблица 3. Влияние удобрений и последействия разных доз известкования на урожайность зеленой массы клевера 1 г.п. в пересчете на абсолютно сухое вещество, т/га

Table 3. The effect of fertilizers and the aftereffect of different doses of liming on the yield of the green mass of clover $1 \mathrm{~g}$. p., in terms of absolutely dry matter, $t / \mathrm{ha}$

\begin{tabular}{|c|c|c|c|c|c|}
\hline \multirow{2}{*}{ Фон NPK (фактор A) } & \multicolumn{3}{|c|}{ Дозы $\mathrm{CaCO}_{3}$, г.к. (фактор В) } & \multirow{2}{*}{$\begin{array}{c}\text { Среднее по } \\
\text { фактору A }\end{array}$} & \multirow{2}{*}{$\begin{array}{c}\text { HCP }_{0,5} \\
\text { (фактор A) }\end{array}$} \\
\hline & 0 & 1,0 & 2,0 & & \\
\hline$(\mathrm{NPK})_{0}$ & 22,6 & 29,0 & 36,2 & 25,1 & \multirow{5}{*}{5,2} \\
\hline$(\mathrm{NPK})_{1}$ & 21,6 & 32,8 & 31,5 & 29,3 & \\
\hline$(\mathrm{NPK})_{2}$ & 35,9 & 39,5 & 28,7 & 32,5 & \\
\hline$(\mathrm{NPK})_{3}$ & 41,4 & 31,3 & 34,8 & 37,9 & \\
\hline Среднее по фактору В & 30,4 & 33,2 & 32,8 & - & \\
\hline $\mathrm{HCP}_{0,5}$ (фактор В) & \multicolumn{5}{|c|}{6,3} \\
\hline $\mathrm{HCP}_{0,5}$ (факторовА В) & \multicolumn{5}{|c|}{12,7} \\
\hline
\end{tabular}

трольным вариантом на 9,7-14,1\% выявлено в вариантах с последействием применения дозы известкового материала в 1,0 гидролитической кислотности (Ca 1,0 г.к.), как по неудобренным фонам применения минеральных удобрений, так и по двойным и тройным дозам (табл. 2). Между остальными вариантами полевого опыта различий по данному показателю плодородия почвы не обнаружено. При оптимальных погодных условиях 2020 г. размножение и развитие большинства микроорганизмов почвы в посевах клевера 1 г.п. (влияние бобовой культуры на размножение почвенной микрофлоры также сыграло большое значение для ее развития по всем вариантам) практически не зависело от применения изучаемых доз минеральных удобрений.

Основными интегральными показателями активности биологических процессов и экологического состояния почв являются интенсивность почвенного «дыхания» и активность почвенных ферментов.
«Дыхание» почвы - это процесс выделения углекислого газа, образующегося в результате окислительных процессов. Интенсивность выделения $\mathrm{CO}_{2}$ почвой связана с дыханием мелких почвенных беспозвоночных животных, с дыханием корней растительности и особенно с активностью почвенных микроорганизмов и их ферментов. В этом особую роль играют иммобилизованные ферменты. Высокую скорость продуцирования углекислоты объясняют большим запасом живых корней высших растений, интенсивным разложением мертвых растительных остатков и возросшей скоростью оборота микробной биомассы. Дыхание как интегральный показатель биохимической активности почв связано, прежде всего, с ферментативным разрушением органических соединений - продуктов жизнедеятельности.

Интенсивность продуцирования выражают в миллиграммах углекислого газа, выделившегося за сутки на 10 г почвы за 24 часа. Интенсивность дыхания: 0,0-5,0 - очень слабая; 5,1-10,0 - слабая; 10,1-15,0 - средняя; 15,1-25,0 - высокая; более 25 - очень высокая.

Результаты этих исследований по изучению интенсивности дыхания почвы представлены в таблице 2. По результатам наших расчетов выявлено, что интенсивность дыхания почвы во всех изучаемых вариантах - очень слабая и находится в интервале 1,53-3,4 мг $\mathrm{CO}_{2} / 10$ г за 24 ч. При этом различий по данному показателю плодородия почвы нами в вариантах по изучению различных фонов минеральных удобрений и последействия разных доз известкования в условиях 2020 года выявлено не было (табл. 2).

Урожайность - важнейший результативный показатель сельскохозяйственного производства. Она зависит от многих факторов: технологии выращивания, климата, сорта и качества посевного (посадочного) материала, а также целого ряда других параметров, среди которых наибольшее значение будут иметь плодородие почвы и погодные условия. Изменение свойств почвы под влиянием средств химизации следует рассматривать через призму изменения урожайности, которую они обеспечивают, вместе с удобрениями и известкованием (табл. 3).

По результатом наших многолетних исследований видно, что к 2020 году последействия различных изучаемых доз извести в полевом опыте, заложенном в 1978 году, не влияют на изменения уровня урожайности клевера розового 1 г.п.: средняя урожайность зеленой массы (в пересчете на абсолютно сухое вещество) находится в интервале 30,4-32,8 т/га ( НCP $_{05}$ по фактору В-6,3).

Применение изучаемых тройных доз минеральных удобрений позволило повысить среднюю урожайность 
клевера 1 г.п. по сравнению с вариантом с естественным плодородием почвы и вариантом применения одинарных доз до 37,9 т/га, что на 11,9 и 8,6 т/га соответственно выше данных вариантов ( $\mathrm{HCP}_{05}$ по фактору A-5,2). Также достоверная прибавка получена и от применения двойных доз минеральных удобрений по сравнению с выращиванием клевера по естественному плодородию почвы, она составила 7,4 т/га ( $\mathrm{HCP}_{05}$ по фактору A-5,2) (табл. 3).

\section{Выводы}

1. На изменения биологических свойств светло-серой леной почвы (биологическая активность почвы и интенсивность дыхания) в 2020 г. большее влияние оказали погодные условия и сама культура клевера розового, чем изучаемые дозы минеральных удобрений и последействие известкования. Биологическая активность почвы находилась в интервале 16,3-30,4\%. Интенсивность дыхания почвы во всех изучаемых вариантах - очень слабая, находилась в интервале 1,53-3,4 мг $\mathrm{CO}_{2} / 10$ г за 24 ч. Различий по данному показателю плодородия почвы от применения изучаемых различных фонов минеральных удобрений и последействия разных доз известкования в условиях 2020 года выявлено не было.

\section{ЛИTEPATYPA / REFERENCES}

1. Шаповалова Н.Н., Менькина Е.А. Агрохимическое состояние и биологическая активность почвы в последействии длительного применения минеральных удобрений. Известия Оренбургского государственного аграрного университета. 2018;(5(73)): 43-46. Режим доступа: https://cyberleninka. $\mathrm{ru} /$ article/n/agrohimicheskoe-sostoyanie-i-biologicheskayaaktivnost-pochvy-v-posledeystvii-dlitelnogo-primeneniyamineralnyh-udobreniy [Дата обращения 5.02.2021]. Shapovalova N. N., Mitkina E. A. Agrochemical state and biological activity of the soil in the aftereffect of long-term application of mineral fertilizers. Proceedings of the Orenburg State Agrarian University. 2018;(5(73)): 43-46. Mode of access: https://cyberleninka. $\mathrm{ru} /$ article/n/agrohimicheskoe-sostoyanie-i-biologicheskayaaktivnost-pochvy-v-posledeystvii-dlitelnogo-primeneniyamineralnyh-udobreniy[Date accessed 5.02.2021] (In Russ.)].

2. Комиссарова В. С., Богомолова Ю. А., Сюбаева А. О., Влияние длительного последействия известкования и систематического применения удобрений на кислотность светло-серой лесной почвы. Плодородие. 2018;(2(101):6-8. Режим доступа: http://www.agriscience.ru/journal/1994-8603/2018/2\%20 (101)/6-8 [Дата обращения 5.02.2021]. Komissarova V. S., Bogomolova Yu. A., Syubaeva A. O., The effect of long-term aftereffect of liming and systematic application of fertilizers on the acidity of light gray forest soil. Fertility. 2018; 2(101):6-8. Access mode: http://www.agriscience.ru/journal/1994-8603/2018/2\%20 (101)/6-8[Accessed 5.02.2021] (In Russ.)]

3. Борисова Е.Е. Роль клевера лугового в экологизации и биологизации земледелия.Символ науки. 2016; 4: 56-61. https://os-russia.com/journal-simvol-nauki [Дата обращения 5.02.2021]. Borisova E. E. The role of meadow clover in ecologization and biologization of agriculture.A symbol of science. 2016; 4: 56-61. https://os-russia.com/journal-simvol-nauki [Accessed 5.02.2021] (In Russ.)].

4. Сирокин И.Б., Сиротина Е.А. Известкование - один из факторов повышения плодородия почв томской области. Агрохимический вестник. 2019; 1: 7- 10. Режим доступа: https:// elibrary.ru/item.asp?id=36984579 [Дата обращения 5.02.2021]. Sirotkin I. B., Sirotina E. A. Liming - one of the factors of increasing soil fertility in the Tomsk region. Agrochemical Bulletin. 2019; 1: 7- 10. Access mode: https://elibrary.ru/item.asp?id=36984579 [Accessed 5.02.2021] (In Russ.)].

5. Биккинина Л.М.-Х, Яппаров И.А., Ломако Е.И., Алиев
2. К 2020 году последействия различных изучаемых доз извести не влияют на изменения уровня урожайности клевера розового 1 г.п.: средняя урожайность зеленой массы (в пересчете на абсолютно сухое вещество) находилась в интервале 30,4-33,2 т/га ( HCP $_{05}$ по фактору В-6,3). Применение изучаемых тройных доз $\left(\mathrm{N}_{45} \mathrm{P}_{120} \mathrm{~K}_{180}\right)$ минеральных удобрений повышает среднюю урожайность клевера розового1 г.п. по сравнению с естественным плодородием светло-серой лесной почвы и вариантом применения одинарных доз $\left(\mathrm{N}_{15} \mathrm{P}_{40} \mathrm{~K}_{60}\right)$ до 37,9 т/га, что на 11,9 и 8,6 т/га соответственно выше данных вариантов $\left(\mathrm{HCP}_{05}\right.$ по фактору A-5,2). Прибавка получена и от применения двойных доз $\left(\mathrm{N}_{30} \mathrm{P}_{80} \mathrm{~K}_{120}\right)$ минеральных удобрений по сравнению с выращиванием клевера по естественному плодородию почвы, она составила 7,4 т/га (HCP $_{05}$ по фактору $A-5,2)$.

3. В целом за 42 года изучения последействия применения известкового материала показано, что оно исчерпало свои возможности, даже по высоким дозам внесения доломитовой муки, и не влияет в условиях юго-востока Волго-Вятского региона на биологические свойства светло-серой лесной почвы и урожайность клевера розового 1 г.п. Почва нуждается в проведении повторных мелиоративных работ.

ША., Газизов Р.Р., Суханова И.М., Ильясов М.М. Химическая мелиорация в условиях безотвальной системы основной обработки почвы. Достижение науки и техники АПК. 2018; 9 (32): 5-8. Режим доступа: DOI:10.24411/0235-2451-2018-10901[Дата обращения 5.02.2021]. Bikkinina L. M.-X, Yapparov I. A., Lomako E. I., Aliev Sh. A., Gazizov R. R., Sukhanova I. M., Ilyasov M. $M$. Chemical melioration in the conditions of a non-fallow system of basic tillage. Achievement of agricultural science and technology. 2018; 9 (32): 5-8. Access mode: DOI: 10.24411/0235-2451-201810901[Date accessed 5.02.2021] (In Russ.)].

6. Кодочилова Н.А., Бузынина Т.С., Варламова Л.Д., Катерова Е.А. Влияние систематического внесения минеральных удобрений и длительного последействия известкования на органическое вещество светло-серой лесной почвы. Аграрная наука Евро-Северо-Востока. 2020; 21(2): 160-168. https:// doi.org/10.30766/2072-9081.2020.21.2.160-168[Дата обращения 5.02.2021]. Kodochigova N. A., Puzynina T. S., Varlamova L. D., Kotyurova E. A. Influence of systematic application of mineral fertilizers and long-term aftereffect of liming on the organic matter of light-gray forest soil. Agrarian science of the Euro-NorthEast. 2020; 21(2): 160-168. https://doi.org/10.30766/20729081.2020.21.2.160-168 [Accessed 5.02.2021] (In Russ.)].

7. Попов Ф.А., Абашев В.Д., Носкова Е.Н., Светлакова Е.В., Лыскова И.В. Влияние длительного применения минеральных удобрений на урожайность и качество зерна озимой ржи. Аграрная наука Евро-Северо-Востока. 2020;21(5):561570. https://doi.org/10.30766/2072-9081.2020.21.5.561570[Дата обращения 5.02.2021]. Popov F.A., Abashev V.D., Noskova E.N., Svetlakova E.V., Lyskova I.V. Influence of longterm use of mineral fertilizers on the yield and quality of winter rye grain. Agricultural Science Euro-North-East. 2020;21(5):561570. https://doi.org/10.30766/2072-9081.2020.21.5.561-570 [Accessed 5.02.2021] (In Russ.)].

8. Ивенин А.В., Саков А.П. Влияние систем обработки светло-серой лесной почвы на урожайность и качество зерна овса в Нижегородской области. Аграрная наука Евро-Северо-Востока. 2020; 21(5): 580- 588. https://doi.org/10.30766/20729081.2020.21.5.580-588[Дата обращения 5.02.2021]. Ivenin A.V., Sakov A.P. The effect of light-gray forest soil tilling systems on the yield and quality of oat grain in the Nizhny Novgorod region. Agricultural Science Euro-North-East. 2020;21(5):580588. https://doi.org/10.30766/2072-9081.2020.21.5.580588[Accessed 5.02.2021] (In Russ.) ]. 